\title{
Correlations between ovarian follicular blood flow and superovulatory responses in ewes
}

\author{
Maria E.F. Oliveira ${ }^{a}$, Marcus A.R. Feliciano ${ }^{a}$, Carla C. D'Amato ${ }^{a}$, \\ Luís G. Oliveira ${ }^{\mathrm{a}}$, Sony D. Bicudo ${ }^{\mathrm{b}}$, Jeferson F. Fonseca ${ }^{\mathrm{c}}$, Wilter R.R. Vicente ${ }^{\mathrm{a}}$, \\ Elise Visco $^{\mathrm{d}}$, Pawel M. Bartlewski ${ }^{\mathrm{d}, *}$ \\ a Department of Preventative Veterinary Medicine and Animal Reproduction, College of Agricultural and Veterinary Sciences, São Paulo \\ State University, Jaboticabal, São Paulo 14.884-900, Brazil \\ b Department of Animal Reproduction and Veterinary Radiology, Faculty of Veterinary Medicine and Animal Science, São Paulo State \\ University, Botucatu, São Paulo 18.618-970, Brazil \\ c Brazilian Agricultural Research Corporation-Embrapa Goats and Sheep, Coronel Pacheco, Minas Gerais 36.155-000, Brazil \\ d Department of Biomedical Sciences, Ontario Veterinary College, University of Guelph, Guelph, ON N1G 2W1, Canada
}

\section{A R T I C L E I N F O}

\section{Article history:}

Received 19 August 2013

Received in revised form 7 October 2013

Accepted 24 October 2013

Available online 7 November 2013

\section{Keywords:}

Ewe

Superovulation

Color Doppler sonography

Blood flow

Antral follicles

\begin{abstract}
A B S T R A C T
The primary goal of this study was to employ ultrasonography to examine the ovaries of ewes undergoing superovulatory treatment for correlations between antral follicular blood flow and ovarian responses/embryo yields. Five Santa Inês ewes were subjected to a short- (Days 0-6, Group 1) and five to a long-term progesterone-based protocol (Days $0-12$, Group 2) to synchronize estrus and ovulations after the superovulatory treatment. Porcine FSH (pFSH, $200 \mathrm{mg}$ ) was administered in 8 decreasing doses over 4 days, starting on Days 4 and 10 in Groups 1 and 2, respectively. After CIDR removal, all ewes were bred by a ram and embryos were recovered surgically 7 days later. Transrectal ovarian ultrasonography was performed the day before and on all 4 days of the superovulatory treatment. Both an arbitrary-scale [(0) non-detectable; (1) small; (2) moderate; (3) intense blood flow] and quantitative analysis of the blood flow area were used to assess the follicular blood flow in color Doppler images. There were no significant correlations between the arbitrary blood flow scores and superovulatory responses in the ewes of the present study. However, there was a positive correlation between the quantitative estimates of follicular blood flow on the final day of the superovulatory treatment, and the number (DA: $r=0.68, P<0.05$; DA/TA $\times 100 \%: r=0.85, P<0.05$ ) and percentage (DA: $r=0.65, P<0.05$; DA/TA $\times 100 \%: r=0.91, P<0.001$ ) of unfertilized eggs (DA: Doppler area, TA: total area of the largest ovarian cross section). This experiment presents a commercially practical tool for predicting superovulatory outcomes in ewes and evidence for the existence of follicular blood flow threshold that may impinge negatively on oocyte quality when surpassed during hormonal ovarian superstimulation.
\end{abstract}

(c) 2013 Elsevier B.V. All rights reserved.
* Corresponding author. Tel.: +1 519824 4120x53330; fax: +1 5197671450 .

E-mail address: pmbart@uoguelph.ca (P.M. Bartlewski).

\section{Introduction}

The outcome of superovulatory treatments in sheep is dependent on a number of different intrinsic and extrinsic factors including, but not limited to, the season, breed, age, plane of nutrition, follicle-stimulating hormone (FSH) products and doses used, type of estrus 
synchronization and insemination, and interval between successive treatments (Gordon, 1997; Cognie et al., 2003; Gonzalez-Bulnes et al., 2004; Shipley et al., 2007). In recent years, the methods of superovulation in sheep have evolved from upgrading hormones to technological advancements (Alexander et al., 2010). Follicle-stimulating hormone (FSH) has been used since the 1980s when studies demonstrated that it resulted in a higher production of transferable quality embryos than pregnant mare serum gonadotropin that was the common choice at the time (PMSG; D’Alessandro et al., 1996). A few modified protocols have been devised to maximize superovulatory yields in small ruminants (Shipley et al., 2007; Menchaca et al., 2010). Despite these and several other improvements, the lack of predictability and tremendous variation in ovarian response and embryo yields/quality continues to be a critical issue in multiple ovulation and embryo transfer (MOET) programs. Predicting the outcome of hormonal ovarian superstimulation is financially vital to commercial MOET ventures, has important practical advantages, and is imperative in expanding the application of superovulation in reproductive research (Bartlewski et al., 2008).

Color Doppler sonography models vascularity and blood flow in body tissues and organs on ultrasound imaging (Fleischer and Andreotti, 2005). It is currently used in a wide range of clinical and diagnostic applications, particularly in obstetrics and gynecology when assessing the ovaries, uterus, fetus or placenta. It has also been used to monitor ovarian blood flow and ovarian responses to hormonal treatments during in vitro fertilization protocols in women (Zaidi et al., 1996).

During antral follicular growth, there is an increased blood supply to the theca layer comprising the outer wall of ovarian antral follicles (Lass and Brinsden, 1999; Matsui and Miyamoto, 2009). Increased blood flow and velocity are also associated with the ovulatory process, and there are no apparent differences in these two parameters between spontaneous and induced ovulations (Lass and Brinsden, 1999). The use of color Doppler sonography to predict ovarian responses after hormonal ovarian superstimulation has recently been studied in cows (Matsui and Miyamoto, 2009) and horses (Witt et al., 2012), but to the best of the authors' knowledge, a similar study has not been conducted in sheep or any other polyovulatory species.

The follicular blood flow velocity prior to ovulation and the duration of the preceding estrus/ovulation synchronization method may both affect ovarian responses and oocyte competence. Hence, the objective of the present study in Santa Inês ewes was to assess antral follicular blood flow during superovulatory porcine $\mathrm{FSH}$ (pFSH) treatment and to compare a semi-quantitative and quantitative approach to analyzing color Doppler sonography images for predicting the superovulatory response after a short- ( 6 days) or long-term (12 days) progesterone-based synchronization protocol.

\section{Materials and methods}

The present study was performed on ten anestrous Santa Inês ewes (aged 2-3 years, mean body weight: $42.0 \pm 1.8 \mathrm{~kg}$ ) housed in the research facility in
Jaboticabal, São Paulo, Brazil ( $21^{\circ} 15^{\prime}$ S, $48^{\circ} 17^{\prime}$ W). All ewes were kept in an outdoor paddock with an easy access to a covered pen protecting them from extensive sunlight and heat. The ewes of the present study had lambed twice prior to the present experiment. Animals received daily balanced feed ratios containing corn silage ( $200 \mathrm{~g} /$ ewe/day) and had unlimited access to water and mineral salt licks.

Five ewes were subjected to a short-(Days 0-6, Group 1) and five to a long-term, progesterone-based protocol (Days $0-12$, Group 2; CIDR $^{\circledR}$, Pfizer-New Zealand) to synchronize estrus and ovulations after follicle-stimulating hormone (pFSH) superovulatory regimen (Fig. 1). All ewes received two injections of $37.5 \mu \mathrm{g}$ of D-cloprostenol (Prolise ${ }^{\circledR}$, Arsa, Argentina) on Day 0 and at CIDR removal. The superovulatory regimen consisted of 8 i.m. injections of pFSH (Folltropin ${ }^{\circledR}-\mathrm{V}$; Bioniche Animal Health, Belleville, ON, Canada) administrated twice daily $(40,40,30,30,20,20$, 10 and $10 \mathrm{mg}$ ). A single i.m. dose of $300 \mathrm{IU}$ of equine chorionic gonadotropin (eCG; Novormon ${ }^{\circledR}$, Syntex, Buenos Aires, Argentina) was given at the time of CIDR withdrawal. Subsequently, all ewes were bred by a fertile ram and embryos were recovered surgically 7 days later.

The ova/embryos were collected by laparotomy under general anesthesia. Each uterine horn was flushed with $40 \mathrm{ml}$ of flushing media $\left(\mathrm{DPBS}^{\circledR}{ }^{\circledR}\right.$, Cultilab, Brazil) at $37^{\circ} \mathrm{C}$. Flushing media were injected via a $20 \mathrm{G}$ catheter inserted at the proximal portion of the uterine horn and collected via a no. 10 Foley catheter inserted at the uterine bifurcation. All recovered eggs and embryos were enumerated and the embryos were maintained in holding media (Holding Plus ${ }^{\circledR}$, Cultilab, Brazil). Morphological evaluation was performed under a stereomicroscope (40× magnification) using the International Embryo Transfer Society (IETS) criteria. Briefly, the embryos that developed to the morula or blastocyst stage at the time of collection were graded from one to four (1-4), with Grade 1 being excellent, Grade 2-good/fair, Grade 3-poor and Grade 4-degenerated (Lindner and Wright, 1993; Rubianes et al., 1995).

Transrectal ovarian ultrasonography was performed the day before and on all 4 days of the superovulatory treatment. Ultrasonographic examinations were carried out by one experienced operator using the color Doppler and Bmode ultrasound system (MyLab VET 30, ESAOTE, Italy) equipped with a stiffened, variable frequency $(6-8 \mathrm{MHz})$, linear-array transducer. Ewes were restrained in a standing position and the abdominal wall was compressed to facilitate the visualization of the uterus and ovaries. The rectum was lubricated using hydrosoluble contact gel prior to insertion of the transducer; the probe was positioned perpendicularly to the abdominal wall and the bladder was identified to orientate the visualization of the uterine horns. The probe was then rotated laterally to both sides to obtain the images of the ovaries and ovarian antral follicles.

B-mode ultrasonography was used to visualize and measure all ovarian antral follicles $\geq 3 \mathrm{~mm}$ in diameter at $1.5-3 \times$ image magnification and variable depths. The mean diameter (average of two dimensions, vertical and horizontal) of each identified follicle was taken from still images. After identification of the follicles, the color Doppler was used to determine intraovarian blood flow. The settings of the scanner (Doppler sampling frequency $(\mathrm{PRF})=1.4 \mathrm{kHZ}$ 


\begin{tabular}{|c|c|c|}
\hline Day & Group 1 $(n=5)$ & Group 2 $(n=5)$ \\
\hline 0 & CIDR & CIDR \\
\hline 1 & CIDR & CIDR \\
\hline 2 & CIDR & CIDR \\
\hline 3 & CIDR & CIDR \\
\hline 4 & CIDR & CIDR \\
\hline 5 & CIDR & CIDR \\
\hline 6 & CIDR removal day & CIDR \\
\hline 7 & & CIDR \\
\hline 8 & & CIDR \\
\hline 9 & & CIDR \\
\hline 10 & & CIDR \\
\hline 11 & & CIDR \\
\hline 12 & & CIDR removal day \\
\hline 13 & & \\
\hline
\end{tabular}

CIDR - Controlled Internal Drug Release device

- $37.5 \mu \mathrm{g}$ of D-cloprostenol i.m.

- porcine FSH treatment (200 mg of pFSH given i.m. in 8 decreasing doses over 4 days)

- Ultrasound and color Doppler imaging

$\square-300 \mathrm{IU}$ of equine chorionic gonadotropin (eCG) i.m.

Fig. 1. A timeline of the superovulatory treatments in two groups of Santa Inês ewes (each $n=5$ ). subjected to either short- (Group 1 ) or long-term estrus synchronization protocol (Group 2).
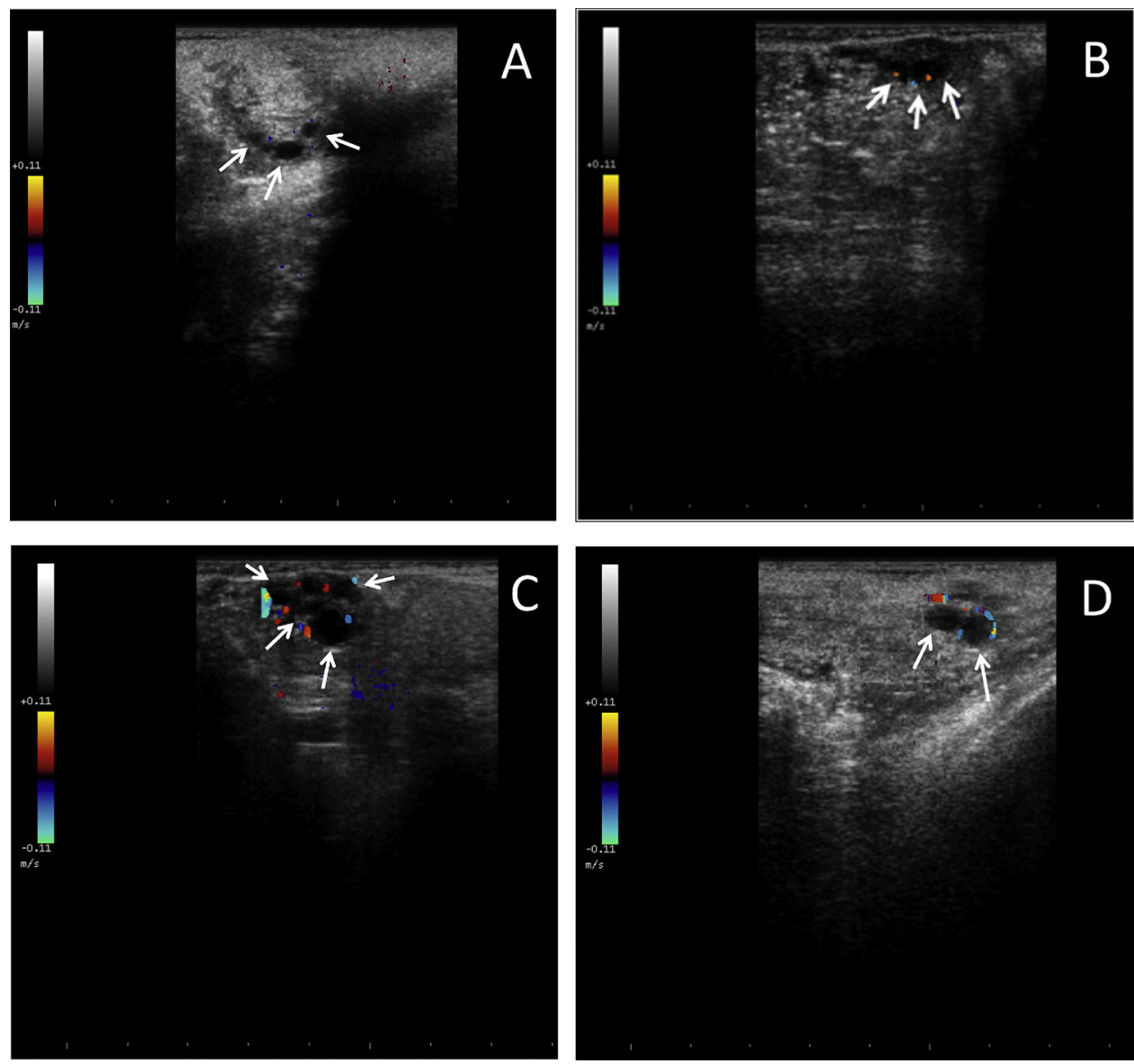

Fig. 2. Color Doppler ultrasonograms of ovine ovaries obtained during the superovulatory porcine follicle-stimulating hormone (pFSH) treatment of anestrous Santa Inês ewes and classified as exhibiting non-detectable (A), small (B), moderate (C) or intense (D) blood flow (arbitrary scale: 0-3). White arrows indicate ovarian antral follicles. 
and color gain $=70 \%$ or just below the background noise level recorded in a motionless animal) remained constant for the duration of the study.

Both an arbitrary-scale [(0) non-detectable; (1) small; (2) moderate; (3) intense blood flow; Fig. 2] and quantitative analysis of the blood flow area (Image $J^{\circledR}$ ) were used to assess the follicular blood flow in Doppler images. In the still images containing the cross-sectional area of the ovary with the strongest color Doppler signal, the ovary was outlined manually and the total ovarian area (TA) recorded. Subsequently, the color Doppler area (DA) representing follicular blood flow was computed for each ovary. Finally, a Doppler Area percentage (DA/TA $\times 100 \%)$ was obtained for each day and for each Santa Inês ewe.

All data were analyzed on a per ewe basis. Single time-point observations were compared between the two groups of ewes by Student's t-test. Proportions of ewes with viable/degenerated embryos and unfertilized eggs were compared by $\chi^{2}$-test (Brandt and Snedecor formula for the analysis of proportions). Two-way repeated measures ANOVA (SigmaPlot ${ }^{\circledR}$ for Windows ${ }^{\circledR}$, Version 11.0, Systat Software Inc., USA) was used to analyze changes in follicular diameters, ovarian cross-sectional area and blood flow in the two groups of animals over time. Holm-Sidak test was used for a post-ANOVA comparison of individual mean values. All data sets that failed normality and/or equal variance tests were transformed by the natural logarithm prior to analyses. Correlations between ovarian responses (number of corpora lutea and unovulated luteinized follicles), superovulatory yields (number of unfertilized eggs, numbers and percentages of unfertilized ova, viable and degenerated embryos, and embryo recovery rates), follicle sizes, and blood flow scores were determined using Pearson Product Moment analyzes. Differences and correlations with $P<0.05$ were considered statistically significant. Data were expressed as mean $\pm \mathrm{SEM}$.

\section{Results}

The difference in mean daily numbers of all detectable antral follicles $\geq 3 \mathrm{~mm}$ between the two groups of ewes approached to significance (Group 1: $6.2 \pm 0.4$ and Group 2: $9.2 \pm 1.3$ follicles/ewe; $P=0.06$ ) but there were no significant differences from 1 day before until the end on the superovulatory treatment. Mean daily diameters and the average size of the largest ovarian follicle present (maximum follicle diameter) increased $(P<0.05)$ from 1 day before to 2 days after the beginning of the superovulatory treatment in Group 1, and from the first to the third day of the treatment in Group 2 animals (Fig. 3). Maximum follicle diameter increased $(P<0.05)$ from Day 2 to Day 3 in Group 2 ewes (Day 0 = first day of superovulatory treatment). On the first day of pFSH treatment, Group 1 ewes exceeded $(P<0.05)$ Group 2 animals in mean follicle diameter.

Mean arbitrary blood flow scores increased $(P<0.05)$ between Days 0 and 1 and Days 1 and 2 in both groups of ewes studied, and between Days 2 and 3 of the superovulatory pFSH treatment in Group 2 (Fig. 4). Group 1 ewes had greater $(P<0.05)$ blood flow scores than Group 2 animals on Days 0 and 2 . The mean cross sectional area of the ovaries did not vary between the two groups of ewes nor over time and the difference in daily estimates of the color Doppler area (DA) approached to significance $(P=0.09)$; in both groups of ewes, it appeared to be greatest on the last two days of the superovulatory treatment. The relative color Doppler area $(\mathrm{DA} / \mathrm{TA} \times 100 \%)$ rose $(P<0.05)$ from 1 day before to 2 days after the beginning of the superovulatory treatment in Group 1 ewes.

There were no significant correlations between the arbitrary blood flow scores and superovulatory responses in the ewes of the present study. Positive correlations were recorded between the quantitative estimates of follicular blood flow on the final day of the superovulatory treatment and the number (DA: $r=0.68, P<0.05$; DA $/$ TA $\times 100 \%$ : $r=0.85, P<0.05$ ) and percentage (DA: $r=0.65, P<0.05$; DA/TA $\times 100 \%: r=0.91, \quad P<0.001)$ of unfertilized eggs. Lastly, the correlations between cross sectional ovarian area (TA) and embryo recovery rates on the last two days of the superovulatory treatment approached to significance $(r=0.60, P=0.07$ and $r=0.57, P=0.09$; for the penultimate and last day of the treatment, respectively).

Ovarian responses and embryo yields summarized in Table 1 did not differ $(P>0.05)$ between superovulated ewes subjected to a short-(Group 1) or long-term (Group 2) estrus synchronization protocol. All ewes had luteal structures detected at laparotomy 7 days after CIDR removal. A mean of 5.9 embryos and 3.6 transferable quality embryos (Grades 1-3) were obtained from a donor ewe in this experiment. Only $10 \%$ of all collections contained no embryos and $30 \%$ yielded no viable embryos. In $70 \%$ of the ewes, however, less than the average number of Grade 1-3 embryos was collected. A significant positive correlation was recorded between the numbers of corpora lutea and recovered embryos ( $r=0.76 ; P<0.05$; data not shown).

\section{Discussion}

In cows, the number of small antral follicles with detectable blood flow at the beginning of the gonadotropin treatment may be used to predict the superovulatory response (Matsui and Miyamoto, 2009). A marked increase in ovarian blood flow associated with the development of multiple ovulatory-sized follicles seems to be related to the effectiveness of hormonal ovarian superstimulation in mares (Witt et al., 2012). In humans, clinical research in this area has provided sufficient evidence to suggest that ovarian perfusion is a likely predictor of IVF outcomes (Zaidi et al., 1996). In contrast to those findings in monovulatory species, the results of the present study in Santa Inês sheep do not present a large amount of quantitative relationships between antral follicular blood flow and superovulatory outcomes. The only significant correlations in this study were confined to the final day of the 4-day $\mathrm{pFSH}$ regimen and were, quite unexpectedly, indicative of oocyte quality/fertilizing ability in superovulated ewes.

The blood supply to ovarian antral follicles is closely related to the follicular growth (i.e., number and size of vesicular follicles) and physiological status (i.e., growing vs. atretic), and the color Doppler ultrasonography may be used to assess the thickness of the follicular wall (Matsui and Miyamoto, 2009). However, there were no differences in the number of all follicles $\geq 3 \mathrm{~mm}$ in diameter in the 

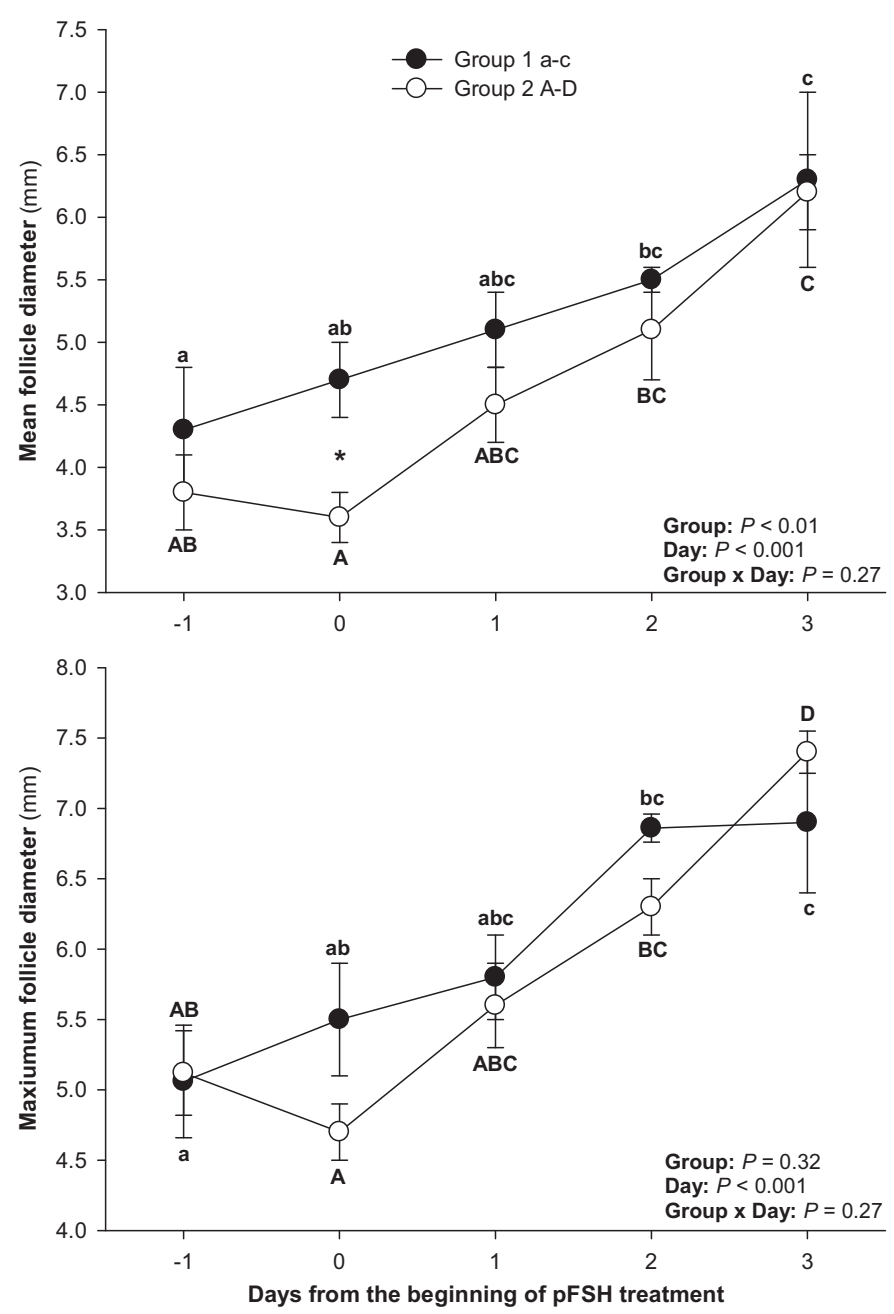

Fig. 3. Mean and maximum daily diameters of all antral follicles $\geq 3 \mathrm{~mm}$ in size detected ultrasonographically in ten anestrous Santa Inês ewes that underwent the multiple-dose, porcine follicle-stimulating hormone (pFSH) treatment after a short- (6 days, Group 1) or long-term progesterone-based protocol (12 days, Group 2 ) to synchronize estrus and ovulations after the superovulatory regimen. a-c, A-D: $P<0.05$; *denotes a significant difference between the two groups.

ewes of the present study and the thickness of the follicular wall does not vary between small, medium-sized and large antral follicles (including preovulatory ovarian follicles) in sheep (Duggavathi et al., 2006). Enhanced production of transferable quality embryos has been reported in cyclic ewes with large numbers of small antral follicles (2-3 mm in diameter; Cognie et al., 2003). However, in a recent study in anestrous ewes, the numbers of small antral follicles at the beginning of the superovulatory treatment were not correlated to superovulatory responses (Bartlewski et al., 2008). Upon further analysis of our present data, no significant correlation was found between follicle size and follicle blood flow, which is similar to the findings of Bollwein et al. (2010). Veiga-Lopez et al. (2006) suggested that large follicle size was related to reduced embryo recovery, fertilization and viability in ewes. However, in a study using an ultrasound-guided follicle aspiration in heifers, oocyte viability did not seem to be directly related to follicular diameter (Vassena et al., 2003) and hence any changes in ovarian perfusion associated with varying sizes of antral follicles present may not be indicative of potential embryo yields and quality after superovulation.

Technical considerations cannot be ruled out as a plausible reason for the lack of more significant results in this study. However, a combination of methods implying inherent accuracy was employed in the present experiment. Experienced operators obtained images of ovarian crosssections limiting any error in this step and a quantification analysis was applied to enhance objectivity and accuracy of results. A more likely case is a limitation in the imaging technology as using the 2D color Doppler sonography, the image acquisition and analysis were restricted to a plane with the strongest Doppler signal. In the ewes of the present study, the ovulation rate ranged from 5 to 26. Therefore, even though the strongest signal in color Doppler sonography was consistently represented in all images, it was likely not a complete representation of the follicular blood flow in the animals with high numbers of growing antral follicles. 

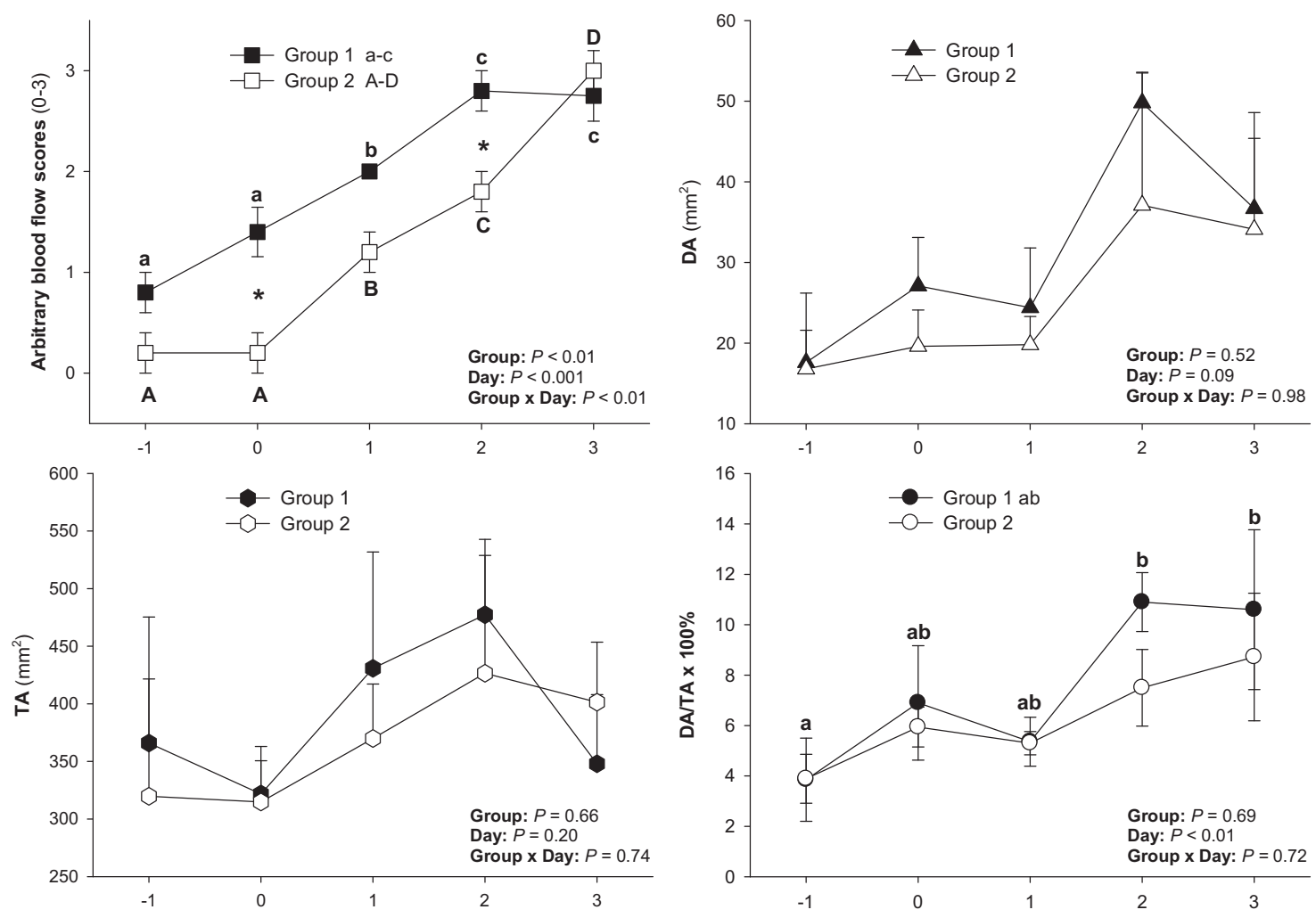

Days from the beginning of $\mathrm{pFSH}$ treatment

Fig. 4. Summary of arbitrary blood flow scores, the color Doppler area (DA), the cross sectional ovarian area (TA), and the relative color Doppler area $(\mathrm{DA} / \mathrm{TA} \times 100 \%)$ determined in ten anestrous Santa Inês ewes that underwent the multiple-dose, porcine follicle-stimulating hormone (pFSH) treatment following a short- ( 6 days, Group 1 ) or long-term progesterone-based estrus synchronization protocol (12 days, Group 2 ). a-c A-D P<0.05; *denotes a significant difference between Group 1 and Group 2 animals.

The direct relationship between the quantitative blood flow estimates on the last day of the superovulatory treatment and the numbers/percentages of unfertilized eggs in Santa Inês ewes is most perplexing. No other trials, to the best of our knowledge, reported the link between high blood flow and reduced oocyte viability. This result directly contradicts the generally accepted opinion that the greater ovarian and follicular blood flow is associated with the greater health of intraovarian structures, primarily because of increased oxygen levels (Van Blerkom et al., 1997; Van Blerkom, 1998; Clark and Stokes, 2011). In cattle, studies have indicated that high blood flow to the preovulatory follicle was associated with increased oocyte recovery, higher incidences of resultant embryo cleavage and development

Table 1

Superovulatory responses after a multiple-dose, 4-day porcine follicle-stimulating hormone (pFSH) treatment initiated in anestrous Santa Inês ewes 4 days (Group 1) or 10 days (Group 2) after insertion of Controlled Internal Drug Release (CIDR) devices.

\begin{tabular}{|c|c|c|c|c|c|c|c|c|c|}
\hline Group & $\begin{array}{l}\text { No. of } \\
\text { CL }\end{array}$ & $\begin{array}{l}\text { No. of } \\
\text { luteinized } \\
\text { unovulated } \\
\text { follicles }\end{array}$ & $\begin{array}{l}\text { No. of viable } \\
\text { embryos } \\
\text { (Grades 1-3) }\end{array}$ & $\begin{array}{l}\text { No. of } \\
\text { unfertilized } \\
\text { eggs }\end{array}$ & $\begin{array}{l}\text { No. of } \\
\text { degenerated } \\
\text { embryos } \\
\text { (Grade } 4 \text { ) }\end{array}$ & $\begin{array}{l}\text { Recovery } \\
\text { rate (\%) }\end{array}$ & $\begin{array}{l}\text { Viability } \\
\text { rate }(\%)\end{array}$ & $\begin{array}{l}\% \text { of } \\
\text { unfertilized } \\
\text { eggs }\end{array}$ & $\begin{array}{l}\% \text { of } \\
\text { degenerated } \\
\text { embryos }\end{array}$ \\
\hline \multirow[t]{5}{*}{1} & 8 & 1 & 2 & 3 & 3 & 100 & 25 & 37.5 & 37.5 \\
\hline & 8 & 1 & 0 & 3 & 2 & 62.5 & 0 & 60 & 40 \\
\hline & 6 & 1 & 4 & 1 & 0 & 83.3 & 80 & 20 & 0 \\
\hline & 10 & 0 & 1 & 6 & 0 & 70 & 14.3 & 85.7 & 0 \\
\hline & 26 & 0 & 18 & 1 & 0 & 73.1 & 94.7 & 5.3 & 0 \\
\hline Mean \pm SEM & $11.6 \pm 3.6$ & $0.6 \pm 0.2$ & $5.0 \pm 3.3$ & $2.8 \pm 0.9$ & $1.0 \pm 0.6$ & $77.8 \pm 6.5$ & $42.8 \pm 18.8$ & $41.7 \pm 14.3$ & $15.0 \pm 9.5$ \\
\hline \multirow[t]{5}{*}{2} & 10 & 0 & 6 & 0 & 3 & 90 & 66.7 & 0 & 33.3 \\
\hline & 15 & 2 & 2 & 0 & 8 & 66.7 & 20 & 0 & 80 \\
\hline & 5 & 0 & 3 & 0 & 1 & 80 & 75 & 0 & 25 \\
\hline & 12 & 0 & 0 & 10 & 0 & 83.3 & 0 & 100 & 0 \\
\hline & 11 & 0 & 0 & 0 & 7 & 63.6 & 0 & 0 & 100 \\
\hline Mean \pm SEM & $10.6 \pm 1.6$ & $0.4 \pm 0.4$ & $2.2 \pm 1.1$ & $2.0 \pm 2.0$ & $3.8 \pm 1.6$ & $76.7 \pm 5.0$ & $32.3 \pm 16.2$ & $20.0 \pm 20.0$ & $47.7 \pm 18.4$ \\
\hline
\end{tabular}


in vitro, and an increased pregnancy rate after embryo transfer (Siddiqui et al., 2009). Similar findings have been obtained in human IVF cycles (Nargund et al., 1996; Van Blerkom et al., 1997).

Antral follicular wall permeability is limited by a distinct blood barrier which prevents a direct contact between maternal blood and ova, protecting the haploid ova from the attack by autologous antibodies as well as any potentially damaging substance in the blood stream. Superovulatory treatments produce supraphysiological levels of blood flow in the ovary. The increased level in blood flow may be associated with an accumulation of serum components in the supporting structure of the ovarian follicles, which would negatively affect the quality but not numbers of ova released after superovulation. However, current research lacks a thorough investigation into this area leaving only logical speculation.

One of such substances could be nitric oxide (NO) that plays a crucial role in folliculogenesis, regulating angiogenesis and steroid production (EL-Sherry et al., 2013). Basini et al. (1998) have demonstrated that treatment with the NO donor reduces progesterone and estradiol production by granulosa cells, possibly by reducing the activity of P450 side-chain cleavage (Basini et al., 1998; Faes et al., 2009). Follicular estradiol in turn enhances NO production and may cause a rapid dilation of blood vessels by activating endothelial nitric oxide synthase (eNOS; EL-Sherry et al., 2013). It has been suggested that NO may potentiate the preovulatory actions of luteinizing hormone (LH; EL-Sherry et al., 2013). In ovarian antral follicles, NO may act as both a surviving (Chung et al., 1995) and cytotoxic factor to granulosa cells (Hurwitz et al., 1992; Ellman et al., 1993). It was suggested that NO could be considered a "Janus-faced" molecule, where a signal transduction pathway, activated by a low concentration of NO could be involved in the elimination of cells whose replicative activity is already reduced whereas high levels of NO are cell-protective (Basini et al., 1998). Anteby et al. (1996) found an inverse correlation between ovarian artery pulsatility index and $\mathrm{NO}_{3} / \mathrm{NO}_{2}$ concentrations in follicles. This could lead to the concept of a threshold value where an exceptionally high level of blood flow to the ovary would potentially result in a low level of NO triggering a detrimental signaling pathway (Basini et al., 1998). In the present study, the two sheep with DA/TA $\times 100 \%$ values close to $20 \%$ had ostensibly more unfertilized eggs. However, the specific reason(s) for a higher blood flow in some of the ewes remain unknown.

There was a discrepancy between the blood flow estimates using the arbitrary scale or quantitative analysis. One explanation may reside in human error. As the color Doppler imaging is not selective for follicular blood flow, the vasculature around and supplying the ovary were also present in the ultrasonographic images. For some images, evaluators may have scaled higher due to the unintentional bias from the presence of other than follicular blood flow sources. Another possibility is that ovarian area may have increased without follicular blood flow increasing in the plane of image acquisition, which has contributed to the differences found in the results of this study. Lass and Brinsden (1999) have demonstrated that a greater size of follicles is associated with a greater ovarian volume. Interestingly, the sectional ovarian area (TA) on the last 2 days of the pFSH treatment tended to be positively correlated with embryo recovery rate suggesting that an increased ovarian volume may be associated with higher ovulation rates and/or improved gamete/embryo transport after superovulation.

To summarize, this study presents a practical tool in a commercial and research setting to aid in predicting ovarian responses and superovulatory yields in sheep. The results of the present study indicate that there exists a threshold in follicular blood flow levels that impinges negatively on oocyte quality. However, additional research into the links between follicular blood flow and the percentage of viable embryos is essential in further establishing, to the best of our knowledge, this novel finding. More research is also needed to deduce why certain ewes responded to the superovulatory protocols differently, with some exhibiting much higher blood flow, although this may very well be due to individual predispositions. Finally, it is also possible that a 4-day ovarian stimulation protocol is less likely to be successful compared with a 3-day pFSH treatment because the negative correlation between the increased blood flow and oocyte quality was found only on the fourth day of the superovulatory treatment.

\section{Acknowledgements}

This study was kindly supported by FAPESP and the preliminary results were presented at the Annual Meeting of the Polish Society for Biology of Reproduction (February 27-March 1, 2013 in Gdańsk, Poland; http://www. sciencedirect.com/science/journal/1642431X; Reproductive Biology (Elsevier), Volume 13, Supplement 2, p. 61 (February 2013).

\section{References}

Alexander, B., Mastromonaco, G., King, W.A., 2010. Recent advances in reproductive biotechnologies in sheep and goat. J. Vet. Sci. Tech. 1, 101, http://dx.doi.org/10.4172/2157-7579.1000101.

Anteby, E., Hurwitz, A., Korach, O., Revel, A., Simon, A., Finci-Yeheskel, Z Mayer, M., Laufer, N., 1996. Human follicular nitric oxide pathway: relationship to follicular size, oestradiol concentrations and ovarian blood flow. Hum. Reprod. 11, 1947-1951.

Bartlewski, P.M., Alexander, B.D., King, W.A., 2008. Ovarian and endocrine determinants of superovulatory responses in anestrous ewes. Small Ruminant Res. 75, 210-216.

Basini, G., Baratta, M., Ponderato, N., Bussolati, S., Tamanini, C., 1998. Is nitric oxide an autocrine modulator of bovine granulosa cell function? Reprod. Fertil. Dev. 10, 471-478.

Bollwein, H., Prost, D., Ulbrich, S.E., Niemann, H., Homnens, A., 2010. Effects of a shortened preovulatory follicular phase on genital blood flow and endometreial hormone receptor concentrations in Holstein-Friesian cows. Theriogenology 73, 242-249.

Chung, S.Y., Eisenhauer, K.M., Kubo, M., Hsueh, A.J., 1995. Interleukin-1b suppresses apoptosis in rat ovarian follicles by increasing nitric oxide production. Endocrinology 136, 3120-3127.

Clark, A.R., Stokes, Y.M., 2011. Follicle structure influences the availability of oxygen to the oocyte in antral follicles. Comput. Math. Method. Med. 2011, 19.

Cognie, Y., Baril, G., Poulin, N., Mermillod, P., 2003. Current status of embryo technologies in sheep and goats. Theriogenology 59 , $171-188$

D’Alessandro, A., Martemucci, G., Toteda, F., Gambacorta, M., Manchisi, A. 1996. Superovulation and embryo production in ewes using a commercial pFSH. Small Ruminant Res. 19, 255-261. 
Duggavathi, R., Janardhan, K., Singh, J., Singh, B., Barrett, D.M.W., Davies, K.L., Bagu, E.T., Rawlings, N.C., 2006. Patterns of expression of steroidogenic enzymes during the first wave of the ovine estrous cycle as compared to the preovulatory follicle. Anim. Reprod. Sci. 91, 345-352.

Ellman, C., Corbett, J.A., Misko, T.P., McDaniel, M., Beckerman, K.P., 1993. Nitric oxide mediated interleukin-1-induced cellular cytotoxicity in the rat ovary: a potential role for nitric oxide in the ovulatory process. J. Clin. Invest. 92, 3053-3056.

EL-Sherry, T.M., Derar, R., Bakry, R., 2013. Changes in blood flow in ovine follicles and serum concentration of estradiol 17 beta (E2) and nitric oxide (NO) around the time of ovulation in Ossimi ewes. Anim. Reprod. Sci., http://dx.doi.org/10.1016/j.anireprosci.2013.02.019.

Faes, M.R., Caldas-Bussiere, M.C., Viana, K.S., Dias, B.L., Costa, F.R., Escocard, R.M., 2009. Nitric oxide regulated steroid synthesis by bovine antral granulosa cells in a chemically defined medium. Anim. Reprod. Sci. $110,222-236$

Fleischer, A.C., Andreotti, R.F., 2005. Colour Doppler sonography in obstetrics and gynecology. Expert Rev. Med. Devices 2, 605-611.

Gonzalez-Bulnes, A., Baird, D.T., Campbell, B.K., Cocero, M.J., Garcia-Garcia, R.M., Inskeep, E.K., Lopez-Sebastian, A., McNeilly, A.S., SantiagoMoreno, J., Souza, C.J.H., Veiga-Lopez, A., 2004. Multiple factors affecting the efficiency of multiple ovulation and embryo transfer in sheep and goats. Reprod. Fertil. Dev. 16, 421-425.

Gordon, I., 1997. Controlled Reproduction in Sheep and Goats. CAB International, New York.

Hurwitz, A., Hernandez, E.R., Payne, D.W., Dharmarajan, A.M., Adashi, E.Y., 1992. Interleukin-1 is both morphogenic and cytotoxic to cultured rat ovarian cells: obligatory role for heterologous, contact-independent cell-cell interaction. Endocrinology 131, 1643-1649.

Lass, A., Brinsden, P., 1999. The role of ovarian volume in reproductive medicine. Hum. Reprod. Update 3, 256-266.

Lindner, G.M., Wright, R.W., 1993. Bovine embryo morphology and evaluation. Theriogenology 40, 713-724.

Matsui, M., Miyamoto, A., 2009. Evaluation of ovarian blood flow by colour Doppler ultrasound: practical use for reproductive management in the cow. Vet. J. 181, 232-240.

Menchaca, A., Vilariño, M., Crispo, M., de Castro, T., Rubianes, E., 2010. New approaches to superovulation and embryo transfer in small ruminants. Reprod. Fertil. Dev. 22, 113-118.
Nargund, G., Bourne, T., Doyle, P., Parsons, J., Cheng, W., Campbell, S., Collins, W., 1996. Associations between ultrasound indices of follicular blood flow, oocyte recovery and preimplantation embryo quality. Hum. Reprod. 11, 109-113.

Rubianes, E., Ibarra, D., Ungerfeld, R., Carbajal, B., de Castro, T., 1995. Superovulatory responses in anestrous ewes is affected by the presence of a large follicle. Theriogenology 43, 465-472.

Siddiqui, M.A., Gastal, E.L., Gastal, M.O., Almamun, M., Beg, M.A., Ginther, O.J., 2009. Relationship of vascular perfusion of the wall of the preovulatory follicle to in vitro fertilization and embryo development in heifers. Reproduction 137, 689-697.

Shipley, C.F.B., Buckrell, B.C., Mylne, M.J.A., Pollard, J., Hunton, J.R., 2007. Artificial insemination and embryo transfer in sheep. Current Therapy in Large Animal Theriogenology, vol. 2. Elsevier, St. Louis, pp. 629-641.

Van Blerkom, J., Antczak, M., Schrader, R., 1997. The developmental potential of the human oocyte is related to the dissolved oxygen content of follicular fluid: association with vascular enothelial growth factor levels and perifollicular blood flow characteristics. Hum. Reprod. 12, 1047-1055.

Van Blerkom, J., 1998. Epigenetic influences in oocyte developmental competence: perifollicular vascularity and intrafollicular oxygen. J. Assist. Reprod. Genet. 15, 226-234.

Vassena, R., Dams, G.P., Mapletoft, R., Pierson, R.A., Singh, J., 2003. Ultrasound image characteristics of ovarian follicles in relation to oocyte competence and follicular status in cattle. Anim. Reprod. Sci. 76, 25-41.

Veiga-Lopez, A., Cocero, M., Dominguez, V., McNeilly, A., Gonzalez-Bulnes, A., 2006. Follicular wave status at the beginning of the FSH treatment modifies reproductive features in superovulated sheep. Reprod. Biol. 6, 243-264.

Witt, M.C., Bollwein, H., Probst, J., Baackmann, C., Squires, E.L., Sieme, H., 2012. Doppler sonography of the uterine and ovarian arteries during a superovulatory program in horses. Theriogenology 77 , $1406-1414$

Zaidi, J., Barber, J., Kyei-Mensah, A., 1996. Relationship of ovarian stromal blood flow at baseline ultrasound to subsequent follicular response in an in vitro fertilisation program. J. Obstet. Gynaecol. 88, 779-784. 